Case Report

\title{
Double Bolus Thrombolysis for Suspected Massive Pulmonary Embolism during Cardiac Arrest
}

\author{
Gerard O’Connor, ${ }^{1}$ Gareth Fitzpatrick, ${ }^{2}$ Ayman El-Gammal, ${ }^{2}$ and Peadar Gilligan ${ }^{2}$ \\ ${ }^{1}$ Department of Emergency Medicine, Mater Misericordiae University Hospital, Eccles Street, Dublin 7, Ireland \\ ${ }^{2}$ Department of Emergency Medicine, Beaumont Hospital, Beaumont Road, Dublin 9, Ireland \\ Correspondence should be addressed to Gerard O’Connor; geroconnor@me.com
}

Received 28 July 2015; Revised 27 October 2015; Accepted 28 October 2015

Academic Editor: Kazuhito Imanaka

Copyright ( $\odot 2015$ Gerard O'Connor et al. This is an open access article distributed under the Creative Commons Attribution License, which permits unrestricted use, distribution, and reproduction in any medium, provided the original work is properly cited.

\begin{abstract}
More than $70 \%$ of cardiac arrest cases are caused by acute myocardial infarction (AMI) or pulmonary embolism (PE). Although thrombolytic therapy is a recognised therapy for both AMI and PE, its indiscriminate use is not routinely recommended during cardiopulmonary resuscitation (CPR). We present a case describing the successful use of double dose thrombolysis during cardiac arrest caused by pulmonary embolism. Notwithstanding the relative lack of high-level evidence, this case suggests a scenario in which recombinant tissue Plasminogen Activator (rtPA) may be beneficial in cardiac arrest. In addition to the strong clinical suspicion of pulmonary embolism as the causative agent of the patient's cardiac arrest, the extremely low end-tidal $\mathrm{CO}_{2}$ suggested a massive PE. The absence of dilatation of the right heart on subxiphoid ultrasound argued against the diagnosis of PE, but not conclusively so. In the context of the circulatory collapse induced by cardiac arrest, this aspect was relegated in terms of importance. The second dose of rtPA utilised in this case resulted in return of spontaneous circulation (ROSC) and did not result in haemorrhage or an adverse effect.
\end{abstract}

\section{Introduction}

Acute pulmonary embolism is a common disease with wellrecognised morbidity and mortality [1-3]. It can present with variable, often nonspecific signs and symptoms, and this often leads to delayed diagnosis [4-6]. The TROICA study argued against the indiscriminate use of lysis in those in cardiac arrest [7]. Emergent thrombolysis is however being increasingly utilised for those with immediately lifethreatening complications of pulmonary embolism [8-10].

In this regard, contemporary guidelines [11] suggest administration of thrombolysis for high-risk patients with pulmonary embolism (shock and/or hypotension present) and intermediate risk patients with pulmonary embolism where haemodynamic decompensation is present (as a result of evidence of both RV dysfunction-by echocardiography or CT angiography - and elevated cardiac biomarker levels in the circulation).

High level evidence in respect of thrombolysis of PE during cardiac arrest is lacking. While there are case reports and case series that describe successful resuscitation following administration of systemic thrombolytic therapy during cardiac arrest (from suspected PE) [12-16], there is also literature arguing against its use $[17,18]$. This is in addition to the arguments that arise as a result of the publication bias of successful case reports and case series. Guidelines-including Class I recommendation from the European Society of Cardiology [11] - advocate proceeding with lysis in cardiac arrest associated with confirmed $\mathrm{PE}$ and also proceeding with lysis in cases of cardiac arrest associated with suspected PE $[19,20]$.

The most frequently used emergency thrombolysis dosing regimen for $\mathrm{PE}$ in cardiac arrest remains the prototypical 2003 British Thoracic Society regime of alteplase $50 \mathrm{mg}$ intravenous (IV) bolus [21]. It is unclear on the optimum approach in those in which first-dose bolus systemic thrombolysis fails to achieve return of spontaneous circulation (ROSC). Options may involve a decision to administer a second bolus of thrombolysis, catheter directed thrombolysis, or other intervention. Extra-corporeal life support [22, 23] and 
surgical embolectomy [11, 20, 24-26] are treatment options in massive PE, although the decision on these options becomes even more complicated in those in cardiac arrest. This case of successful resuscitation following double dose thrombolysis should help to inform the decision making process for those facing a similar dilemma in the future.

\section{Case}

A 39 year-old gentleman presented to the Emergency Department with a two-day history of pleuritic chest pain, lethargy and associated symptoms of progressively increasing shortness of breath (now occurring with minimal exertion). This occurred on a background of more long-standing nonspecific lethargy. There was a history of a recent long-haul flight from Nigeria to Ireland one week previously. At presentation, he exhibited a tachycardia of 116 beats per minute, blood pressure of $131 / 94 \mathrm{mmHg}$, and a respiratory rate of 22 breaths per minute.

An electrocardiogram revealed a sinus tachycardia with symmetrical $\mathrm{T}$ wave inversion in praecordial lead V3. Arterial blood gas analysis showed $\mathrm{PaO}_{2}$ of $7.5 \mathrm{kPa}, \mathrm{PaCO}_{2}$ of $3.8 \mathrm{kPa}$, $\mathrm{pH} 7.47$, and an oxygen saturation of $89 \%$. A D-dimer assay performed at triage was significantly elevated at $10.5 \mathrm{mg} / \mathrm{L}$. Given the working diagnosis of probable pulmonary embolus (high-risk pretest probability), therapeutic low-molecularweight heparin (Enoxaparin $120 \mathrm{mg}$ subcutaneously) was administered prior to emergent Computed Tomographic Pulmonary Angiography (CTPA).

Two hours later, while awaiting emergent CTPA, the patient collapsed and was found to be in cardiac arrest. Cardiopulmonary resuscitation was promptly initiated for pulseless electrical activity (PEA). Intubation with a cuffed oroendotracheal tube (COETT) was achieved without interruption of chest compressions. Despite primary confirmation of COETT placement, end-tidal $\mathrm{CO}_{2}$ was not detected initially. Subxiphoid ultrasound-performed during brief interruption of chest compressions-did not reveal a dilated right side of heart. Despite this, given the overall clinical picture at this juncture, a presumptive diagnosis of massive or saddle pulmonary embolus was made.

Along with conventional ACLS adrenaline therapy, rtPA (alteplase) $50 \mathrm{mg}$ was promptly administered. Despite continuing high quality chest compressions and a gradual rise in quantitative end-tidal $\mathrm{CO}_{2}$, no cardiac output was detected after twenty minutes. A decision was taken to administer a second bolus of rtPA (alteplase) $50 \mathrm{mg}$. Ten minutes subsequent to this and following on-going advanced life support, return of spontaneous circulation (ROSC) was achieved with an initial non-invasive blood pressure of 144/50 $\mathrm{mmHg}$.

Standard post-ROSC resuscitation care was instituted and this gentleman was admitted to the intensive care unit. A CTPA demonstrated multiple bilateral pulmonary emboli. He was continued on Enoxaparin and bridged to Warfarin once critical care stability was achieved. No major (or minor) bleeding was observed during this gentleman's hospital stay. The patient ultimately recovered to hospital discharge with a Glasgow Outcome Score of 4, secondary to watershed cerebellar infarcts.

\section{Discussion}

A number of trials and guidelines address the issue of thrombolysis during a massive pulmonary embolism and submassive pulmonary embolism. There are few specific guidelines which directly address the issue of thrombolysis during cardiac arrest in those with (suspected) massive pulmonary embolism [27], that is, fulminant cases.

The British Thoracic Society (BTS) recommends a bolus of $50 \mathrm{mg}$ alteplase for massive PE [21] and states that this may be "instituted on clinical grounds alone if cardiac arrest is imminent." The American Heart Association seems to recommend a two-hour infusion of $100 \mathrm{mg}$ of alteplase in those with haemodynamic compromise (though they do not explicitly address the issue of cardiac arrest) [28]. The 2014 European Society of Cardiology Guidelines [11] recommend a dose of $100 \mathrm{mg} \mathrm{rtPA}$ over 2 hours or $0.6 \mathrm{mg} / \mathrm{kg}$ over 15 minutes [29], though again they are not explicit regarding the approach in cardiac arrest. We felt that a prolonged infusion might not represent the best approach in the situation presented, given the understandable exigencies of cardiac arrest.

There are numerous case reports and case series describing survival post thrombolysis in cardiac arrest caused by PE. Er et al. [30] retrospectively studied 104 patients in whom thrombolysis was administered for presumptive PE cardiac arrest. ROSC was achieved in 40 patients with survival to hospital discharge in 19 patients. Both ROSC and survival to hospital discharge were associated with earlier initiation of thrombolysis. Patients in this trial were treated with bolus dose rtPA with an average dose of $80.5 \pm 24 \mathrm{mg}$. Janata et al. [31] describe a retrospective review of cardiac arrest patients with the cause of arrest secondary to massive PE. Sixtysix patients were reviewed with 36 of these patients treated with rtPA. They administered rtPA as a bolus of $0.6-1.0 \mathrm{mg}$ $\mathrm{rtPA} / \mathrm{kg}$ body weight up to a maximum of $100 \mathrm{mg}$ of $\mathrm{rtPA}$. Return of spontaneous circulation showed a trend towards improvement in the rtPA group (67\% versus $43 \%, P=0.06$ ) as well as survival to discharge (19\% versus $7 \%, P=0.15)$.

Once thrombolysis is initiated for a suspected PE in cardiac arrest, guidelines suggest that CPR should be continued for at least 60-90 minutes [13, 32-36].

Domino or double dose thrombolysis also appears in the literature. In the sentinel study by Böttiger et al. [37], 90 patients were assigned to intervention (thrombolysis) or control arms of treatment for cardiac arrest. Those in the intervention arm received a bolus of $5000 \mathrm{IU}$ of heparin with $50 \mathrm{mg}$ rtPA after $15 \mathrm{~min}$ of unsuccessful CPR, with a repeat bolus of heparin and rtPA 30 minutes later if ROSC was not achieved. While there is no breakdown on the numbers receiving double dose thrombolysis, in this early study on thrombolysis in cardiac arrest they noted statistically significant increases in ROSC and survival to hospital admission in the thrombolysis group. Kürkciyan et al. [38] describe intervening with regimens of $100 \mathrm{mg} \mathrm{rtPA}$ (either as a $50 \mathrm{mg}$ double bolus or as a bolus dose of $15 \mathrm{mg}$, followed by continuous infusion of $85 \mathrm{mg}$ over 90 minutes). In this intervention arm the two survivors to hospital discharge received double bolus doses. Similarly Fengler and Brady [39], in their suggested treatment algorithm, advocate a 
repeat bolus of alteplase $50 \mathrm{mg}$ if ROSC is not achieved after 15 minutes after the first dose. In our case, we cannot discount that, despite achievement of ROSC after the second bolus, this success might be better explained by the haemodynamic improvements brought about by the first bolus [40].

There is general consensus that thrombolysis should be considered in cardiac arrest where pulmonary embolism is strongly suspected. The exact dosage and timing of fibrinolysis remain to be clarified $[7,19,37,41]$, though there does appear to be a trend towards improved survival in those in whom intervention is initiated at an earlier juncture. This is seen in the study by Er et al. [30] in which those patients who survived to hospital discharge benefitted from earlier initiation of lysis compared to all other patients $(11.0 \pm 1.3$ versus $22.5 \pm 0.9 \mathrm{~min} ; P<0.001)$. The issue of risks and benefits in terms of haemorrhage remains a major consideration and while the principle of primum non nocere is more difficult to weigh in those in cardiac arrest, it should be remembered that the bleeding risks remain significant. Evidence would suggest that thrombolysis does not seem to be unduly associated with catastrophic haemorrhage in this critically ill patient group [31, 42, 43]; nevertheless there are still recognised major haemorrhage rates and intracranial haemorrhage rates of up to $10.4 \%$ [44] and $3.6 \%$ [45] in contemporary prospective trials.

Low end-tidal $\mathrm{CO}_{2}\left(\mathrm{ETCO}_{2}\right)$ is seen both in cardiac arrest [46-48] and in massive pulmonary embolism [49-55]. Increases in $\mathrm{ETCO}_{2}$ are seen in recovery from both entities and have prognostic value in those in cardiac arrest in predicting the likelihood of ROSC [56]. The unrecordable levels seen at the outset of this case were assumed to result from the absolute no flow through the pulmonary circulation rather than the low flow that is seen in cardiac arrest.

Common echocardiographic findings in massive pulmonary embolism include that of an enlarged right ventricle [57] which may be associated with a flattened interventricular septum (D-sign of interventricular septal shift) and the "McConnell" sign [58, 59]. These tests were originally described in those with massive PE (and were originally performed with transthoracic approaches rather than with subxiphoid views) so their validity and applicability in terms of positive and negative predictive value for patients in cardiac arrest are unknown. Therefore, the absence of the echocardiographic features should not be used to rule out PE as a cause of cardiac arrest [60].

In conclusion, this particular case describes a clinical scenario in which double dose thrombolysis was successfully used. A similar strategy might be contemplated in the future by emergency physicians dealing with cardiac arrest caused by massive pulmonary embolism.

\section{Conflict of Interests}

The authors declare that they have no conflict of interests regarding this paper.

\section{Authors' Contribution}

All authors provided advice and guidance on the development and preparation of the paper.

\section{References}

[1] S. B. Smith, J. B. Geske, J. M. Maguire, N. A. Zane, R. E. Carter, and T. I. Morgenthaler, "Early anticoagulation is associated with reduced mortality for acute pulmonary embolism," Chest, vol. 137, no. 6, pp. 1382-1390, 2010.

[2] J. L. Carson, M. A. Kelley, A. Duff et al., "The clinical course of pulmonary embolism," The New England Journal of Medicine, vol. 326, no. 19, pp. 1240-1245, 1992.

[3] V. F. Tapson, "Acute pulmonary embolism," The New England Journal of Medicine, vol. 358, no. 10, pp. 990-1052, 2008.

[4] P. D. Stein, A. Beemath, F. Matta et al., "Clinical characteristics of patients with acute pulmonary embolism: data from PIOPED II," The American Journal of Medicine, vol. 120, no. 10, pp. 871879, 2007.

[5] P. D. Stein, F. Matta, M. H. Musani, and B. Diaczok, "Silent pulmonary embolism in patients with deep venous thrombosis: a systematic review," American Journal of Medicine, vol. 123, no. 5, pp. 426-431, 2010.

[6] PIOPED Investigators, "Value of the ventilation/perfusion scan in acute pulmonary embolism. Results of the Prospective Investigation of Pulmonary Embolism Diagnosis (PIOPED)," The Journal of the American Medical Association, vol. 263, no. 20, pp. 2753-2759, 1990.

[7] B. W. Böttiger, H.-R. Arntz, D. A. Chamberlain et al., "Thrombolysis during resuscitation for out-of-hospital cardiac arrest," The New England Journal of Medicine, vol. 359, no. 25, pp. 26512662, 2008.

[8] C. Jerjes-Sanchez, A. Ramírez-Rivera, M. de Lourdes García et al., "Streptokinase and heparin versus heparin alone in massive pulmonary embolism: a randomized controlled trial," Journal of Thrombosis and Thrombolysis, vol. 2, no. 3, pp. 227-229, 1995.

[9] B. Ly, H. Arnesen, H. Eie, and R. Hol, "A controlled clinical trial of streptokinase and heparin in the treatment of major pulmonary embolism," Acta Medica Scandinavica, vol. 203, no. 6, pp. 465-470, 1978.

[10] D. A. Tibbutt, J. A. Davies, J. A. Anderson et al., "Comparison by controlled clinical trial of streptokinase and heparin in treatment of life-threatening pulmonary embolism," British Medical Journal, vol. 1, no. 5904, pp. 343-347, 1974.

[11] S. V. Konstantinides and A. Torbicki, "2014 ESC guidelines on the diagnosis and management of acute pulmonary embolism," European Heart Journal, vol. 35, no. 43, pp. 3033-3073, 2014.

[12] M. R. Bailén, J. Á. R. Cuadra, and E. Aguayo De Hoyos, "Thrombolysis during cardiopulmonary resuscitation in fulminant pulmonary embolism: a review," Critical Care Medicine, vol. 29, no. 11, pp. 2211-2219, 2001.

[13] J.-P. Wu, D.-Y. Gu, S. Wang, Z.-J. Zhang, J.-C. Zhou, and R.-F. Zhang, "Good neurological recovery after rescue thrombolysis of presumed pulmonary embolism despite prior 100 minutes CPR," Journal of Thoracic Disease, vol. 6, no. 12, pp. E289-E293, 2014.

[14] B. W. Böttiger, H. Böhrer, A. Bach, J. Motsch, and E. Martin, "Bolus injection of thrombolytic agents during cardiopulmonary resuscitation for massive pulmonary embolism," Resuscitation, vol. 28, no. 1, pp. 45-54, 1994.

[15] T. Zhu, K. Pan, and Q. Shu, "Successful resuscitation with thrombolysis of a presumed fulminant pulmonary embolism during cardiac arrest," The American Journal of Emergency Medicine, vol. 31, no. 2, pp. 453.e1-453.e3, 2013.

[16] Q. Yin, X. Li, and C. Li, "Thrombolysis after initially unsuccessful cardiopulmonary resuscitation in presumed pulmonary 
embolism," The American Journal of Emergency Medicine, vol. 33, no. 1, pp. 132.e1-132.e2, 2015.

[17] R. B. Abu-Laban, J. M. Christenson, G. D. Innes et al., “Tissue plasminogen activator in cardiac arrest with pulseless electrical activity," The New England Journal of Medicine, vol. 346, no. 20, pp. 1522-1528, 2002.

[18] N. Kucher, E. Rossi, M. De Rosa, and S. Z. Goldhaber, "Massive pulmonary embolism," Circulation, vol. 113, no. 4, pp. 577-582, 2006.

[19] E. J. Lavonas, I. R. Drennan, A. Gabrielli et al., "Part 10: special circumstances of resuscitation: 2015 American Heart Association guidelines update for cardiopulmonary resuscitation and emergency cardiovascular care," Circulation, vol. 132, no. 18, supplement 2, pp. S501-S518, 2015.

[20] A. Truhlar, C. D. Deakin, J. Soar et al., "European Resuscitation Council Guidelines for Resuscitation 2015: section 4. Cardiac arrest in special circumstances," Resuscitation, vol. 95, pp. 148201, 2015.

[21] British Thoracic Society Standards of Care Committee Pulmonary Embolism Guideline Development G, "British Thoracic Society guidelines for the management of suspected acute pulmonary embolism," Thorax, vol. 58, no. 6, pp. 470-483, 2003.

[22] G. Maj, G. Melisurgo, M. De Bonis, and F. Pappalardo, "ECLS management in pulmonary embolism with cardiac arrest: which strategy is better?" Resuscitation, vol. 85, no. 10, pp. e175e176, 2014.

[23] J. Swol, D. Buchwald, J. Strauch, and T. A. Schildhauer, "Extracorporeal life support (ECLS) for cardiopulmonary resuscitation (CPR) with pulmonary embolism in surgical patients-a case series," Perfusion, 2015.

[24] I. E. Konstantinov, P. Saxena, M. D. Koniuszko, J. Alvarez, and M. A. J. Newman, "Acute massive pulmonary embolism with cardiopulmonary resuscitation: management and results," Texas Heart Institute Journal, vol. 34, no. 1, pp. 41-46, 2007.

[25] H. C. Doerge, F. A. Schoendube, H. Loeser, M. Walter, and B. J. Messmer, "Pulmonary embolectomy: review of a 15year experience and role in the age of thrombolytic therapy," European Journal of Cardio-Thoracic Surgery, vol. 10, no. 11, pp. 952-957, 1996.

[26] N. Meneveau, M.-F. Séronde, M.-C. Blonde et al., "Management of unsuccessful thrombolysis in acute massive pulmonary embolism," Chest, vol. 129, no. 4, pp. 1043-1050, 2006.

[27] K. P. Goran, “Thrombolysis during cardiopulmonary resuscitation should be addressed in guidelines for pulmonary embolism," European Heart Journal, vol. 29, no. 24, pp. 3066-3067, 2008.

[28] M. R. Jaff, M. S. McMurtry, S. L. Archer et al., "Management of massive and submassive pulmonary embolism, iliofemoral deep vein thrombosis, and chronic thromboembolic pulmonary hypertension: a scientific statement from the American Heart Association," Circulation, vol. 123, no. 16, pp. 1788-1830, 2011.

[29] S. V. Konstantinides, A. Torbicki, G. Agnelli et al., 2014 ESC Guidelines on the Diagnosis and Management of Acute Pulmonary Embolism-Web Addenda, 2014, http://www.escardio .org/static_file/Escardio/Guidelines/publications/APEAcute PE_ Web Addenda.pdf.

[30] F. Er, A. M. Nia, N. Gassanov, E. Caglayan, E. Erdmann, and U. C. Hoppe, "Impact of rescue-thrombolysis during cardiopulmonary resuscitation in patients with pulmonary embolism," PLoS ONE, vol. 4, no. 12, article e8323, 2009.

[31] K. Janata, M. Holzer, I. Kürkciyan et al., "Major bleeding complications in cardiopulmonary resuscitation: the place of thrombolytic therapy in cardiac arrest due to massive pulmonary embolism," Resuscitation, vol. 57, no. 1, pp. 49-55, 2003.

[32] B. W. Böttiger and E. Martin, "Thrombolytic therapy during cardiopulmonary resuscitation and the role of coagulation activation after cardiac arrest," Current Opinion in Critical Care, vol. 7, no. 3, pp. 176-183, 2001.

[33] F. Spöhr and B. W. Böttiger, "Safety of thrombolysis during cardiopulmonary resuscitation," Drug Safety, vol. 26, no. 6, pp. 367-379, 2003.

[34] C. Nobre, B. Thomas, L. Santos, and J. Tavares, "Prolonged chest compressions during cardiopulmonary resuscitation for in-hospital cardiac arrest due to acute pulmonary embolism," Texas Heart Institute Journal, vol. 42, no. 2, pp. 136-138, 2015.

[35] T. Hsin, F. W. Chun, and H. L. Tao, "Ultra-long cardiopulmonary resuscitation with thrombolytic therapy for a sudden cardiac arrest patient with pulmonary embolism," American Journal of Emergency Medicine, vol. 32, no. 11, pp. 1443.e31443.e4, 2014.

[36] D. K. Pedley and W. G. Morrison, "Role of thrombolytic agents in cardiac arrest," Emergency Medicine Journal, vol. 23, no. 10, pp. 747-752, 2006.

[37] B. W. Böttiger, C. Bode, S. Kern et al., "Efficacy and safety of thrombolytic therapy after initially unsuccessful cardiopulmonary resuscitation: a prospective clinical trial," The Lancet, vol. 357, no. 9268, pp. 1583-1585, 2001.

[38] I. Kürkciyan, G. Meron, F. Sterz et al., "Pulmonary embolism as a cause of cardiac arrest: presentation and outcome," Archives of Internal Medicine, vol. 160, no. 10, pp. 1529-1535, 2000.

[39] B. T. Fengler and W. J. Brady, "Fibrinolytic therapy in pulmonary embolism: an evidence-based treatment algorithm," The American Journal of Emergency Medicine, vol. 27, no. 1, pp. 84-95, 2009.

[40] H. Sors, G. Pacouret, R. Azarian, G. Meyer, B. Charbonnier, and G. Simonneau, "Hemodynamic effects of bolus vs 2-h infusion of alteplase in acute massive pulmonary embolism: a randomized controlled multicenter trial," Chest, vol. 106, no. 3, pp. 712-717, 1994.

[41] J. K. Logan, H. Pantle, P. Huiras, E. Bessman, and L. Bright, "Evidence-based diagnosis and thrombolytic treatment of cardiac arrest or periarrest due to suspected pulmonary embolism," The American Journal of Emergency Medicine, vol. 32, no. 7, pp. 789-796, 2014.

[42] K. H. Scholz, U. Tebbe, C. Herrmann et al., "Frequency of complications of cardiopulmonary resuscitation after thrombolysis during acute myocardial infarction," The American Journal of Cardiology, vol. 69, no. 8, pp. 724-728, 1992.

[43] M. Ruiz-Bailén, A. E. de Hoyos, M. Serrano-Córcoles, M. DíazCastellanos, J. Ramos-Cuadra, and A. Reina-Toral, "Efficacy of thrombolysis in patients with acute myocardial infarction requiring cardiopulmonary resuscitation," Intensive Care Medicine, vol. 27, no. 6, pp. 1050-1057, 2001.

[44] C. Wang, Z. Zhai, Y. Yang et al., "Efficacy and safety of low dose recombinant tissue-type plasminogen activator for the treatment of acute pulmonary thromboembolism: a randomized, multicenter, controlled trial," Chest, vol. 137, no. 2, pp. 254-262, 2010.

[45] C. Becattini, G. Agnelli, A. Salvi et al., "Bolus tenecteplase for right ventricle dysfunction in hemodynamically stable patients with pulmonary embolism," Thrombosis Research, vol. 125, no. 3, pp. e82-e86, 2010.

[46] J. L. Falk, E. C. Rackow, and M. H. Weil, "End-tidal carbon dioxide concentration during cardiopulmonary resuscitation," 
The New England Journal of Medicine, vol. 318, no. 10, pp. 607611, 1988.

[47] A. R. Garnett, J. P. Ornato, E. R. Gonzalez, and E. B. Johnson, "End-tidal carbon dioxide monitoring during cardiopulmonary resuscitation," Journal of the American Medical Association, vol. 257, no. 4, pp. 512-515, 1987.

[48] K. R. Sheak, D. J. Wiebe, M. Leary et al., "Quantitative relationship between end-tidal carbon dioxide and CPR quality during both in-hospital and out-of-hospital cardiac arrest," Resuscitation, vol. 89, pp. 149-154, 2015.

[49] L. Hatle and R. Rokseth, “The arterial to end-expiratory carbon dioxide tension gradient in acute pulmonary embolism and other cardiopulmonary diseases," Chest, vol. 66, no. 4, pp. 352357, 1974.

[50] R. Whitesell, C. Asiddao, D. Gollman, and J. Jablonski, "Relationship between arterial and peak expired carbon dioxide pressure during anesthesia and factors influencing the difference," Anesthesia and Analgesia, vol. 60, no. 7, pp. 508-512, 1981.

[51] C. Yosefy, E. Hay, Y. Nasri, E. Magen, and L. Reisin, "End tidal carbon dioxide as a predictor of the arterial $\mathrm{PCO}_{2}$ in the emergency department setting," Emergency Medicine Journal, vol. 21, no. 5, pp. 557-559, 2004.

[52] U. K. H. Wiegand, V. Kurowski, E. Giannitsis, H. A. Katus, and H. Djonlagic, "Effectiveness of end-tidal carbon dioxide tension for monitoring of thrombolytic therapy in acute pulmonary embolism," Critical Care Medicine, vol. 28, no. 11, pp. 3588-3592, 2000.

[53] A. R. Hemnes, A. L. Newman, B. Rosenbaum et al., "Bedside end-tidal $\mathrm{CO}_{2}$ tension as a screening tool to exclude pulmonary embolism," European Respiratory Journal, vol. 35, no. 4, pp. 735741, 2010.

[54] M. Endoh, I. Yamanaka, and Y. Munetsugu, "Massive pulmonary thromboembolism during an orthopedic surgery in an obese patient," Japanese Journal of Anesthesiology, vol. 62, no. 10, pp. 1203-1206, 2013.

[55] I. Riaz and B. Jacob, "Pulmonary embolism in Bradford, UK: Role of end-tidal $\mathrm{CO}_{2}$ as a screening tool," Clinical Medicine, Journal of the Royal College of Physicians of London, vol. 14, no. 2, pp. 128-133, 2014.

[56] O. Touma and M. Davies, "The prognostic value of end tidal carbon dioxide during cardiac arrest: a systematic review," Resuscitation, vol. 84, no. 11, pp. 1470-1479, 2013.

[57] P. MacCarthy, A. Worrall, G. McCarthy, and J. Davies, "The use of transthoracic echocardiography to guide thrombolytic therapy during cardiac arrest due to massive pulmonary embolism," Emergency Medicine Journal, vol. 19, no. 2, pp. 178-179, 2002.

[58] J. A. Lodato, R. P. Ward, and R. M. Lang, "Echocardiographic predictors of pulmonary embolism in patients referred for helical CT,' Echocardiography, vol. 25, no. 6, pp. 584-590, 2008.

[59] M. V. McConnell, S. D. Solomon, M. E. Rayan, P. C. Come, S. Z. Goldhaber, and R. T. Lee, "Regional right ventricular dysfunction detected by echocardiography in acute pulmonary embolism," American Journal of Cardiology, vol. 78, no. 4, pp. 469-473, 1996.

[60] P.-M. Roy, I. Colombet, P. Durieux, G. Chatellier, H. Sors, and G. Meyer, "Systematic review and meta-analysis of strategies for the diagnosis of suspected pulmonary embolism," British Medical Journal, vol. 331, no. 7511, pp. 259-263, 2005. 


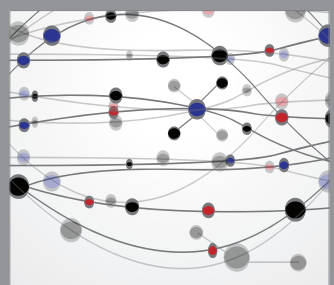

The Scientific World Journal
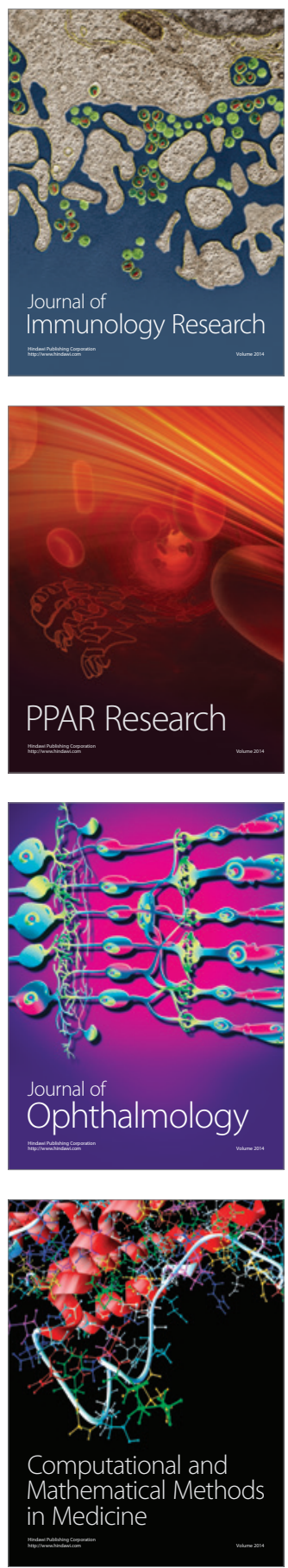

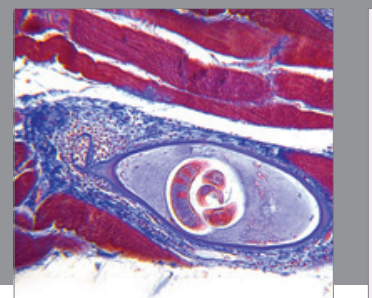

Gastroenterology

Research and Practice
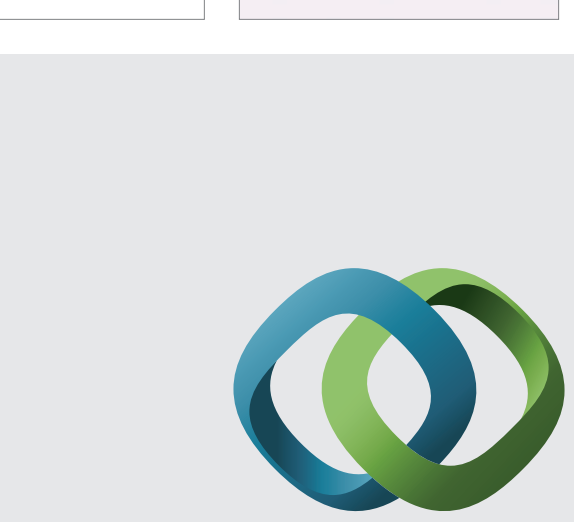

\section{Hindawi}

Submit your manuscripts at

http://www.hindawi.com
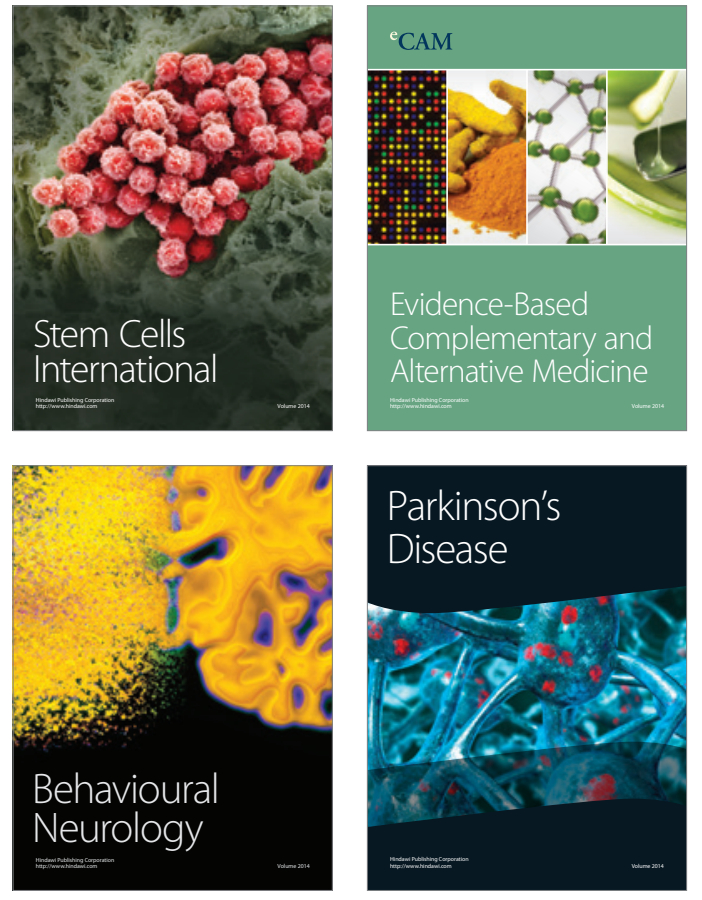
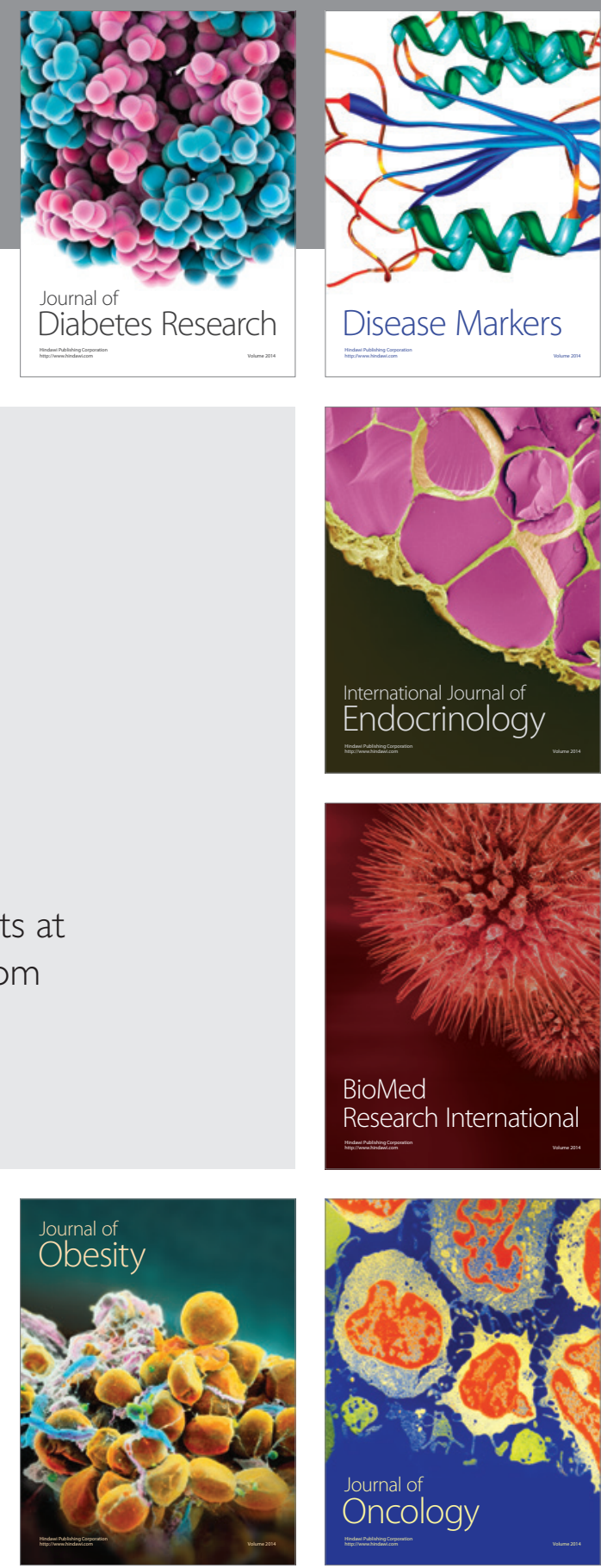

Disease Markers
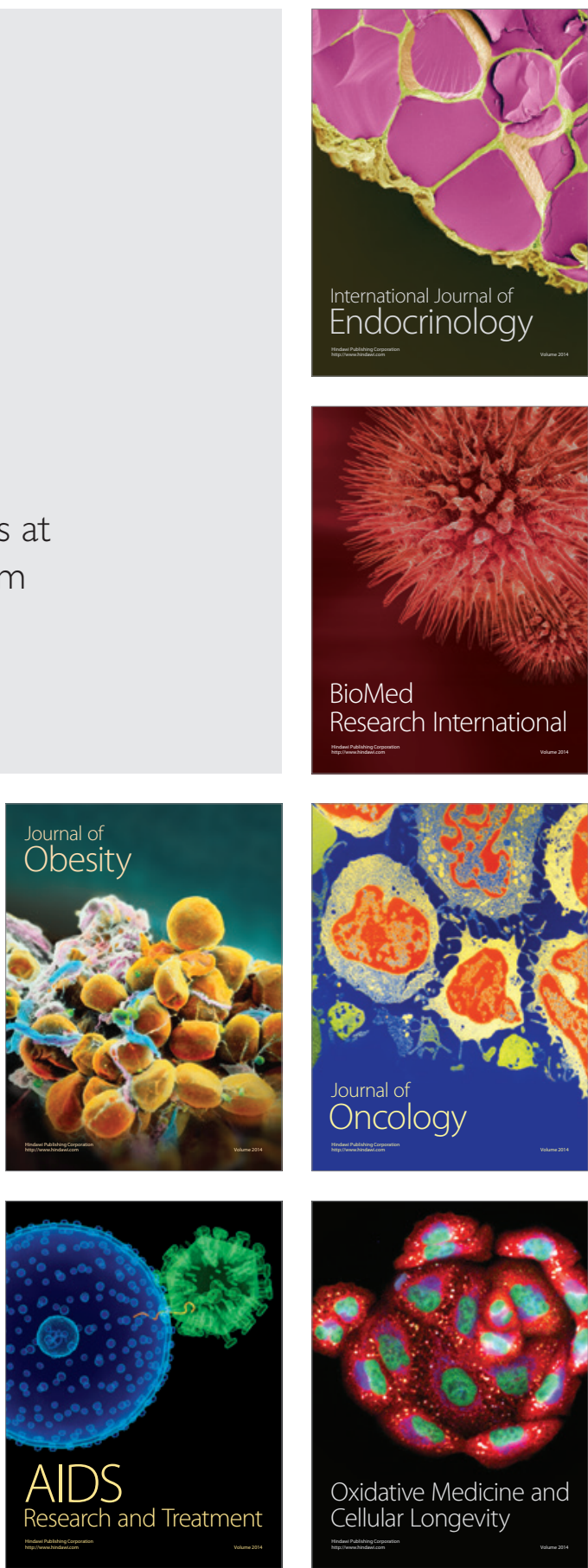